\title{
CONFIGURACIONES CIRCUNFLEJAS EN LA ENTONACIÓN DEL ESPAÑOL MEXICANO
}

\author{
Pedro Martín ButragueÑo \\ El Colegio de México
}

Los años recientes han visto un despertar de los estudios sobre la entonación del español ${ }^{1}$. A los materiales clásicos de Tomás Navarro Tomás y de Antonio Quilis ${ }^{2}$, se ha sumado en los últimos cinco años un llamativo número de libros y de artículos sobre diferentes problemas melódicos del español ${ }^{3}$.

Dos aspectos caracterizan la investigación moderna. Por un lado, el uso sistemático de técnicas instrumentales para determinar los aspectos fonéticos de las curvas melódicas; por otro, la especificación detallada de los aspectos fonológicos de la entonación. En ese sentido, las formulaciones que se vienen usando con más frecuencia se derivan de la llamada fonología métrica autosegmental. Lo que se hace en esta perspectiva fonologica es asignar una serie de

\footnotetext{
1 Este trabajo se ha redactado en el marco del proyecto «Diversidad y variación fónica en las lenguas de Méxicon (CONACYT, 44731H). Una versión previa más reducida se leyó en el XV Congreso de la Asociación Internacional de Hispanistas, celebrado en Monterrey del 19 al 24 de julio de 2004. No se entregó para publicación en las Actas.

2 En particular, el Manual de entonación española de Navarro Tomás (Madrid, Guadarrama, 4." ed, 1974; 1." ed., 1944), y de Quilis la «Entonación dialectal hispánica», Lingǘtstica Española Actual, 7, 1985, págs. 145-190, y el capítulo dedicado a la entonación en el Tratado de fonología y fonética españolas (Madrid, Gredos, 1993, pags. 424-489), entre otros conocidos trabajos.

${ }^{3}$ Entre los libros y los números de revistas dedicados a la entonación total o parcialmente se encuentran Juan Manuel Sosa, La entonación del español. Su estructura fónica, variabilidad y dialectología, Madrid, Cátedra, 1999; Francisco José Cantero, Teoria y analisis de la entonación, Barcelona, Edicions de la Universitat de Barcelona, 2002; Pilar Prieto, Entonació. Models, teoria, mètodes, Barcelona, Ariel, 2002; José Ignacio Hualde, ed., Intonation in Romance, Probus, 14, 1, 2002; Esther Herrera y Pedro Martín Butragueño, eds., La tonía: dimensiones fonéticas y fonológicas, México, El Colegio de México, 2003; Eugenio Martínez Celdrán, dir., Estudios de Fonética Experimental, 12, 2003; Pilar Prieto, ed., Romance Intonation, Catalan Joumal of Linguistics, 2, 2003; Pilar Prieto, coord., Teorías de la entonación, Barcelona, Ariel, 2003. Otro problema es cómo plasmar en la investigación prosódica las diferencias sociolingúísticas dentro de una comunidad de habla. Véase al respecto la propuesta y las consideraciones de Francisco Moreno Fernández, «Ej estudio sociolingúístico de la entonación»», Oralia, 1, 1998, págs. 95-117.
}

RFE, LXXXIV, 2004, 2:ㄱ. págs. 347-373 
acentos tonales, en principio sobre las sílabas tónicas de un enunciado, aunque no exclusivamente. El acento más importante es el nuclear, que en español es el último de la frase. Existen acentos tonales monotonales o simples y bitonales o complejos. Los acentos tonales simples sólo pueden ser altos o bajos, y se escriben de manera convencional como $\mathrm{H}^{*}$ y $\mathrm{L}^{*}$. Los acentos bitonales admiten una combinatoria más variada, del tipo $\mathrm{L}^{*}+\mathrm{H}, \mathrm{L}+\mathrm{H}^{*}$, etcétera, donde la letra con asterisco se ancla a la sílaba tónica y la parte restante, precedente o subsiguiente, sirve para expresar diferentes movimientos melódicos adicionales en la misma sílaba o en las contiguas. Existen también dos tipos de tonos de juntura: $\mathrm{H} \%$ y $L \%$, y quizá $M \%{ }^{4}$, que sirven para marcar los límites iniciales y sobre todo los finales de una frase entonativa, y $\mathrm{H}-$ y $\mathrm{L}$-, que marcan los finales de las llamadas frases intermedias, que son las frases en que puede subdividirse una frase entonativa mayor ${ }^{5}$ :

Acentos monotonales: $\mathrm{H}^{*}, \mathrm{~L}^{*}$.

Acentos bitonales: $\mathrm{L}^{*}+\mathrm{H}, \mathrm{L}+\mathrm{H}^{*}$, etcétera.

Tonos de juntura de frase entonativa: $\mathrm{H} \%, \mathrm{~L} \%$ (y quizá $\mathrm{M} \%$ ).

Tonos de juntura de frase intermedia: $\mathrm{H}-\mathrm{L}$ - .

La altura tonal de los acentos tonales es relativa, y se asigna a la vista de los movimientos melódicos de ascenso o descenso con respecto a los tonos precedentes.

Así, dada la figura 1, en la que vemos, de arriba hacia abajo, la transcripción silábica, el oscilograma, la curva de intensidad y la frecuencia fundamental en $\mathrm{Hz}$, que es el principal dato fonético para caracterizar la entonación ${ }^{6}$,

${ }^{4}$ Cf. Mary E. Beckman, Manuel Díaz-Campos, Julia Tevis McGory y Terrell A. Morgan, «Intonation across Spanish, in the Tones and Break Indices framework», Probus, 14, 2002, págs. 9-36.

${ }^{5} \mathrm{La}$ existencia de H- y L- es polémica en español. Sosa, op. cit., los ha considerado innecesarios: «La noción de acento de frase puede ser menos útil, incluso superflua, en lenguas como el francés, el español, y demás lenguas de núcleo fijo. En estas lenguas, el último acento tonal no puede estar muy lejos del borde derecho de la frase, por lo que un eventual acento de frase no podría generar ningún tipo de contraste» (pág. 87). Otros autores (como Nibert, Hualde, Ortiz-Lira, etc.) sí los han tomado en cuenta. Véanse los muy pertinentes comentarios de José Ignacio Hualde, «El modelo métrico y autosegmental», en Teorías de la entonación, coord. P. Prieto, Barcelona, Ariel, 2003, págs. 167-171. Pero véase Becknan et al., op. cit., págs. 30-31.

${ }^{6}$ El ejemplo es parte del material recogido para «Entre la prosodia y la sintaxis: variación melódica en el estilo de lectura», en Lengua, variación y contexto. Estudios dedicados a Humberto Lopez Morales, ed. F. Moreno et al., Madrid, Arco-Libros, 2003, vol. II, págs. 681-697. 
la trayectoria melódica podría representarse así:

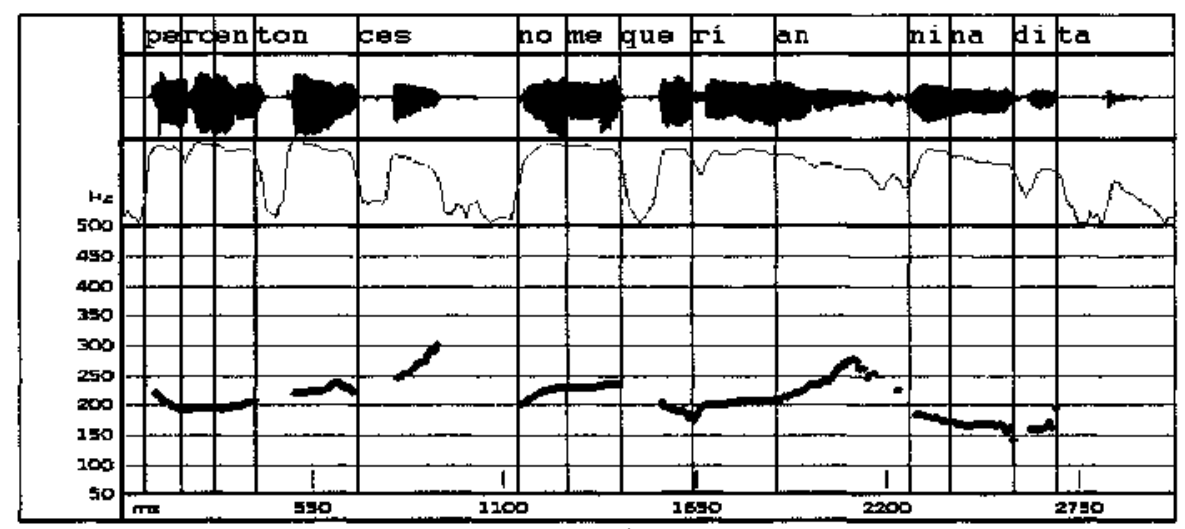

FiguRA 1.-Análisis acústico de Pero entonces no me querian ni nadita.

$$
\begin{aligned}
& \text { [ [pero entonces] [no me querían] [ni nadita] ] }
\end{aligned}
$$

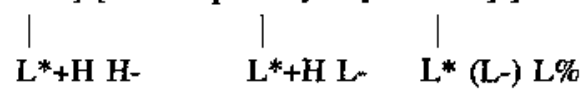

Es decir, se distinguen dos niveles de frases, las intermedias y las entonativas, y se anudan los acentos tonales (marcados con *) sobre las sílabas tónicas, de forma que con el $\mathrm{L}^{*}+\mathrm{H}$ de ton se marca la dirección ascendente del acento tonal, que culmina de hecho en la sillaba siguiente, ascenso continuado en un posible tono de juntura intermedia $\mathrm{H}$-. En la segunda frase intermedia, podríamos marcar de nuevo el nivel relativamente bajo de la silaba $r i$ con el $\mathrm{L}^{*}$ de la primera parte del bitono, el nivel más alto de la postónica con $+\mathrm{H}$, y el descenso que aparece en la parte final de la frase intermedia con el tono Lr. Por fin, el tono de la sílaba di de la última frase intermedia es bajo, $\mathrm{L}^{*}$, el tono de juntura intermedio es redundante en este ejemplo y por eso se pone entre paréntesis, $y$ por fin se asigna un tono de juntura bajo $L \%$ al cierre de la frase entonativa de este enunciado declarativo.

\section{LA ESTRUCTURA CIRCUNFLEJA}

Uno de los fenómenos más llamativamente mencionado para el español de México es la llamada entonación circunfleja. Obsérvense los siguientes ejemplos: 
[sobre la mesa] [puso María el libro]

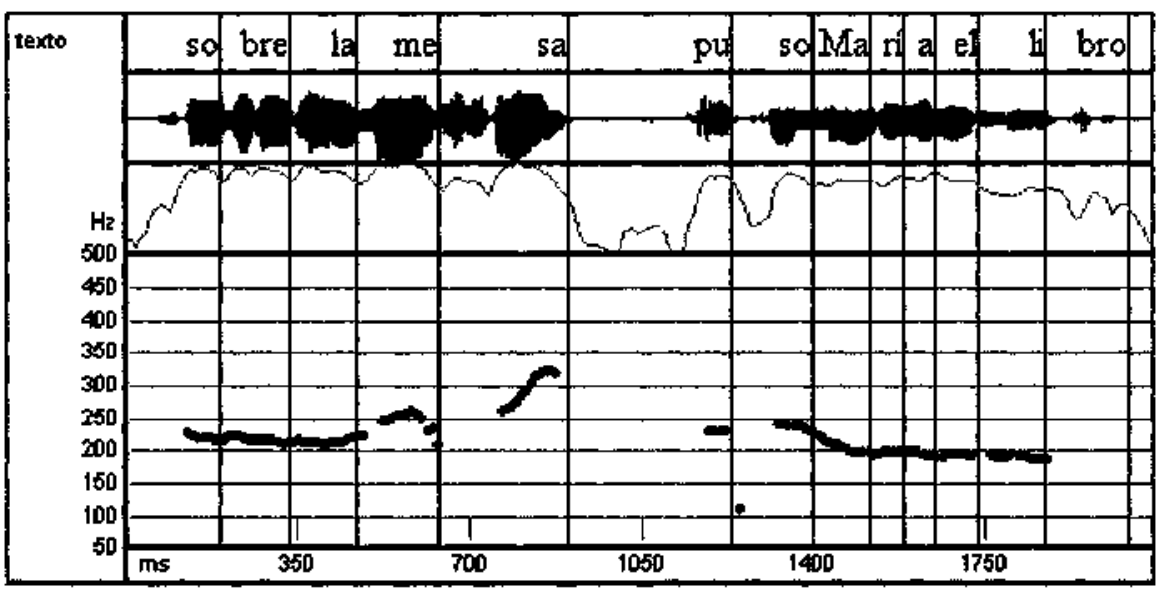

[sobre la mesa] [puso María el libro]

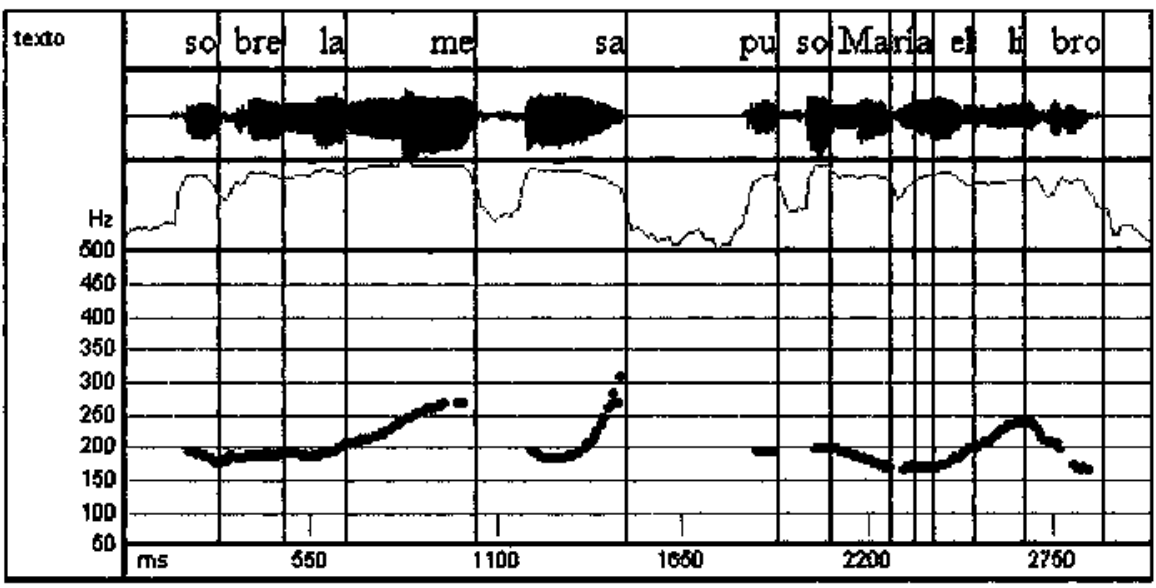

FlgURA 2.-Dos realizaciones de Sobre la mesa puso María el libro.

Aunque estos ejemplos son un poco artificiosos, porque han sido obtenidos por medio de lecturas en el laboratorio ${ }^{7}$, permiten apreciar, al fijarse en la parte final del enunciado, el libro, la diferencia entre una declarativa descendente normal (la primera) y una declarativa circunfleja (la segunda).

? Fueron producidos por dos mujeres jovenes, con estudios superiores, para «La construcción prosódica de la estructura focal en español», en Variación gramatical. Un reto para las teorías de la sintaxis, ed. Valeriano Bellosta von Colbe y Gabriele Knauer, en prensa. 
Ya se refería a este fenómeno Henríquez Ureña en 1938:

Es característica la cadencia final de la frase enunciativa, muy distinta de la cadencia usual en Castilla. En el castellano de Madrid, la frase enunciativa que termina en palabra llana, si no tiene especial intención afectiva, describe una línea descendente al final [...]. En el habla popular de Méjico, de la antepenúltima sílaba a la penúltima se asciende aproximadamente una tercera, y de la penúltima sílaba a la última se desciende aproximadamente una sexta; la penúltima es larga, la final muy breve ${ }^{8}$.

Matluck insistía en la peculiaridad circunfleja de la entonación mexicana en su tesis de $1951^{9}$ y en su artículo de $1952^{10}$, describiéndola en términos muy parecidos a los de Henríquez Ureña. Será en un citado trabajo de 1965 cuando Matluck precise sus observaciones sobre la entonación circunfleja, a la que se otorga un valor solamente fonético ${ }^{11}$. La curva circunfleja del tonema consistiría en un nivel de tono $/ 2 /$ en vez de /1/ para la silaba fuerte, y en una terminación suspensiva $/ \rightarrow /$ en vez de descendente $/ \downarrow /$; en cuanto a la silaba final, a veces puede descender algo y a veces no, y suele alargarse notablemente ${ }^{12}$. Además, la impresión circunfleja se intensifica por la fuerza de las sílabas fuertes y la debilidad de las débiles. Adjuntando las estructuras propuestas por Matluck al ejemplo Tiró la comida, y escribiendo el nivel tonal antes de la sílaba, obtendríamos las siguientes curvas melódicas ${ }^{13}$ :

${ }^{1} \mathrm{Ti}^{2}{ }^{2}$ ró. la. co. ${ }^{1} \mathrm{mi} .{ }^{1} \mathrm{da} \downarrow$ (no circunfleja)

${ }^{1}$ Ti. ${ }^{2}$ tó. la. co. ${ }^{2} \mathrm{mi} .^{1}$ 'da $\rightarrow$ (circunfleja I)

${ }^{1} \mathrm{Ti}^{2}{ }^{2}$ ró. la. co. ${ }^{2} \mathrm{mi} .{ }^{2} \mathrm{da} \rightarrow$ (circunfleja II)

Dentro del análisis de configuraciones empleado por Kvavik en varios trabajos ${ }^{14}$, se distingue entre cadencias simples y complejas. Las primeras son

${ }^{8}$ Pedro Henriquez Ureña, «Mutaciones articulatorias en el habla popular», en El español en Méjico, los Estados Unidos y la América Central, Buenos Aires, Universidad, 1938, pág. 335. Sobre «El estudio de la entonación del español de México» puede verse el recuento que aparecerá en el Homenaje a Paola Bentivoglio.

- Joseph H. Matluck, La pronunciación en el español del Valle de México, tesis, México, UNAM, 1951, págs. xvii-xviii y 122.

to «La pronunciación del español en el Valle de México», Nueva Revista de Filologúa Hispánica, 6, 1952, pág. 119.

11 «Entonación hispánica», Anuario de Letras, 5, 1965, págs. 5-32.

12 Ibíd., pág. 30.

13 Llamo circunflejas I y in a las dos posibilidades descritas por Matluck. Con mayor precisión fonética, Matluck propone que las estructuras circunflejas $/ 21 \rightarrow / /$ y $/ 22 \rightarrow /$ serían en realidad [2.2 1.8: $\rightarrow$ ] y $[2.22: \rightarrow]$. Siguiendo la sugerencia de Martínez Celdrán ("Análisis por niveles: la escuela americana", en Teorias de la entonación, coord. P. Prieto, Barcelona, Arjel, 2003, pág. 72), el detalle fonético puede representarse como $[2+2-\rightarrow]$ y $[2+2 \rightarrow]$.

14 Karen H. Kvavik, "An anaiysis of sentence-initial and final intonational data in two Spanish dialects", Joumal of Phonetics, 2, 1974, págs. 351-361; «Sense-group terminations in Mexican Spanish", en Studies in Honor of Lloyd A. Kasten, Madison, Hispanic Seminary of 
unidireccionales y se desarrollan a partir de la postónica final. Las complejas, en cambio, son más variadas, adoptan diferentes formas (circunflejas, descendentes-ascendentes, en terraplén y escalonadas), en ellas el movimiento cambiante comienza en la sílaba tónica final y son las que se asocian al «acento mexicano" ${ }^{15}$. En cuanto a las cadencias complejas circunflejas, pueden ser suspensivas, descendentes o ascendentes. Además, Kvavik atribuye un valor discursivo diferente a cada una de las estructuras circunflejas:

Cadencia circunfleja suspensiva (sea $\alpha$ ): "clearly emphatic and assertive". Cadencia circunfleja descendente $(\beta)$ : "stronger assertion overbalancing the emphasis".

Cadencia circunfleja ascendente ( $\gamma$ ): "emphasis, but with a demonstrative quality -a hearer orientation" 16.

Según Quilis, el enunciado declarativo mexicano con sentido completo coincidiría con Puerto Rico y Gran Canaria en mostrar un movimiento circunflejo en la parte final del enunciado, con contomo final descendente, aunque aclara que es sólo una de las realizaciones posibles ${ }^{17}$ :

La llamada entonación circunfleja [...presenta...] un movimiento de ascensodescenso en su parte final, de amplio arco; el fundamental siempre termina, con movimiento descendente, a un nivel similar al del cuerpo del enunciado, o más alto. La cima de esta inflexión coincide normalmente con la última vocal tónica.

El fundamental sube desde el comienzo del movimiento ascendente hasta la cima un 33 por ciento para las mujeres y un $\mathbf{4 1 . 6}$ por ciento para los hombres, y desciende un 33 por ciento tanto para los hombres como para las mujeres [...]. La gama de frecuencias sube una media de $59 \mathrm{~Hz}$ para las mujeres y de $29.5 \mathrm{~Hz}$ para los hombres. Desde la cima hasta el final desciende una media de $59 \mathrm{~Hz}$ para las mujeres y de $23.6 \mathrm{~Hz}$ para los hombres ${ }^{18}$.

\footnotetext{
Medieval Studies, 1975, págs. 101-115; «An interpretation of cadences in Mexican Spanish», en Colloquium on Spanish and Luso-Brazilian Linguistics, ed. J. P. Lantolf, F. Wattman Frank y J. M. Guitart, Washington, Georgetown University Press, 1979, págs. 37-47; «Las unidades melódicas en el español mexicano», en Dialectología hispanoamericana. Estudios actuales, ed. G. E. Scavnicky, Washington, Georgetown University Press, 1980, págs. 48-57.

15 «An interpretation», op. cit., pág, 44.

16 id.

17 «Entonación», op. cit., pág. 167; Tratado, op. cit., pág. 456. También en Madrid se llega a producir, según Quilis, la configuración circunfleja, pero sólo con valor expresivo enfático.

18 «Entonación», op. cit., pág. 160.
} 
Los ejemplos que ofrece Quilis son de este tipo ${ }^{19}$ :
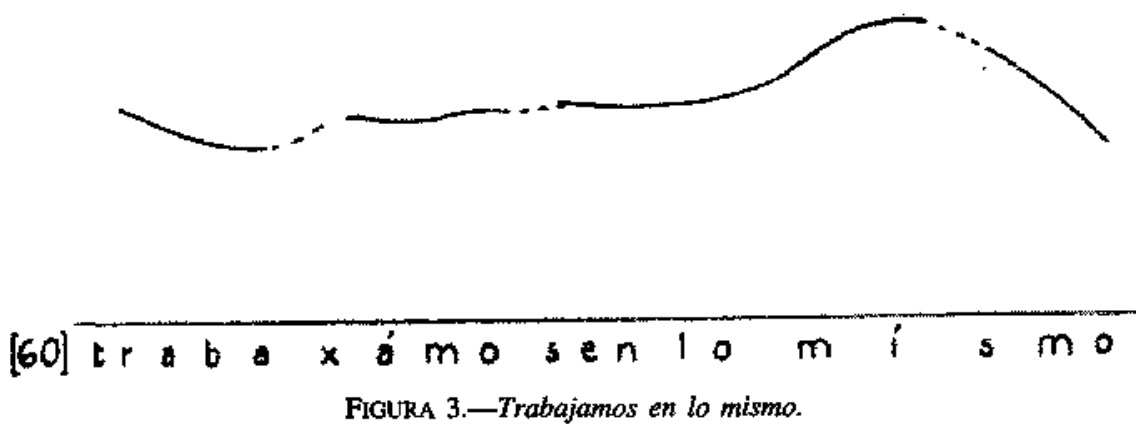

La otra forma de presentarse en México el enunciado declarativo es la general en español, con una frecuencia fundamental descendente, con mayor o menor inclinación ${ }^{20}$.

En un marco autosegmental, Sosa analiza el tonema circunflejo mexicano como $\mathrm{L}+\mathrm{H} * \mathrm{~L} \%{ }^{21}$ :

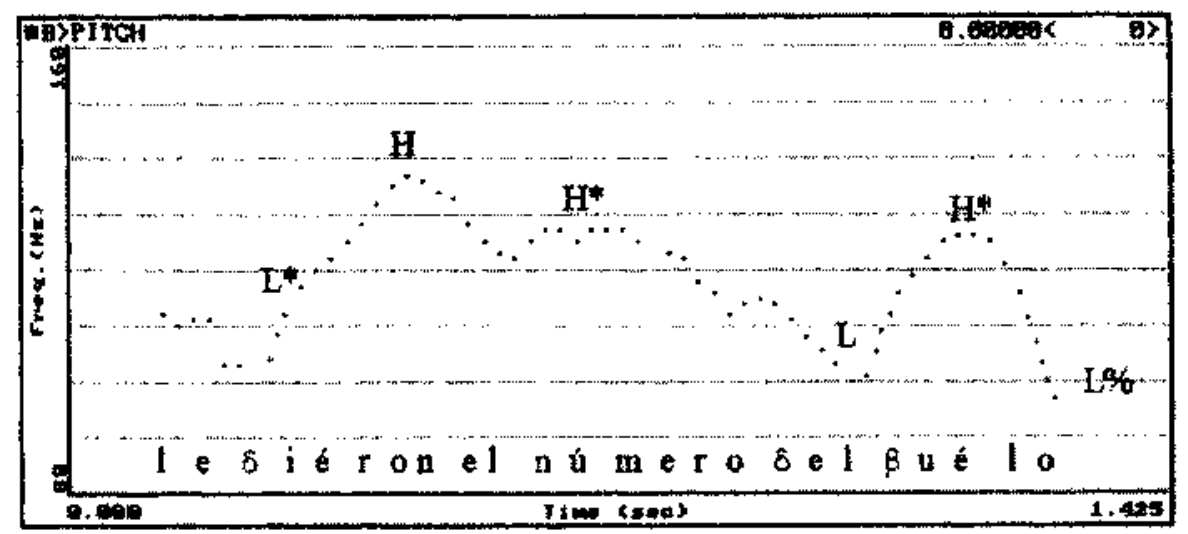

FIGURA 4.- Le dieron el número del vuelo.

La variante descendente se describiría por medio del tonema $L * L \%$, de la que Sosa ofrece ejemplos de Buenos Aires, San Juan de Puerto Rico, La Habana, Sevilla, Pamplona y Madrid. Da también ejemplos de un tonema $\mathrm{H}^{*} \mathrm{~L} \%$ en casos de Bogotá, Caracas y Barcelona, que correspondería a estructuras tam-

19 Tratado, op. cit., pág. 457, ej. 60.

${ }^{20}$ Tratado, op. cit., pág. 483.

${ }^{21}$ Op. cit., págs. 120-121 y 189-190; el ejemplo es la figura 3.3 de la pág. 189. 
bién circunflejas pero en principio no tan marcadas. El caso mexicano sería especial:

Es posible un movimiento final circunflejo como tenninación de los enunciados declarativos, producto de tonemas altos del tipo $\mathrm{H} * \mathrm{~L} \%$ o $\mathrm{L}+\mathrm{H} * \mathrm{~L} \%$. En la mayoría de los casos la dicotomía entre la cadencia simple de $L^{*} L \%$, y la circunfleja tipificada por $\mathrm{H}^{*} \mathrm{~L} \%$ marca, según nuestra interpretación como hablante del español, cierta diferencia de destaque del tonema, que le otorga mayor expresividad a la segunda con respecto a la primera. Una excepción a esta generalización parece ser el caso del enunciado declarativo mexicano circunflejo, aparentemente no causado por motivaciones pragmáticas de ese orden, sino por características dialectales sistemáticas, aunque nuestros datos no nos permiten ser categóricos con respecto a esta materia ${ }^{22}$.

Las circunstancias de uso de los diferentes tonemas posibles en México serían cuestión de pragmática entonativa y deben estudiarse con detenimiento ${ }^{23}$.

Un problema en la representación como $\mathrm{L}+\mathrm{H}^{*}$ del acento tonal nuclear circunflejo es que su representación vendría a coincidir con el tipo de acento que algunos autores sugieren ahora como característico, en general, de esa posición, en coincidencia con el acento focal, también $\mathrm{L}+\mathrm{H}^{*}$ para algunos y a diferencia del acento tonal prenuclear o pretonemático, cuya formulación más común sería $\mathrm{L}^{*}+\mathrm{H}^{24}$.

Existen varias posibilidades para representar el tonema con el caso más marcado de acento circunflejo mexicano, cada una de ellas con diferentes ventajas e inconvenientes. Tres de esas posibilidades son las siguientes:

$\mathrm{L}+\mathrm{H}^{*} \mathrm{H}-\mathrm{L} \%$

$\mathrm{H}+\mathrm{H}^{*} \mathrm{~L} \%$

$\mathrm{L}+\mathrm{iH}^{*} \mathrm{~L} \%$

22 lbíd., pág. 197.

23 Ibíd., pág. 190.

${ }^{24}$ Cf. Timothy L. Face, «Un anáisisis fonológico del acento nuclear en el español de Madrid», en E. Herrera y P. Martín, eds., op. cit., págs. 229-233 y 234-240; Hualde, «El modelo métrico», op. cit., pág. 175. Beckman et al, ibíd., pág. 33, describen $\mathrm{L}^{*}+\mathrm{H}$ como «late rising accent, with peak after the stressed syllabie and valley toward the beginning (prenuclear accent in Mexican Spanish and some Peninsular varieties, focal accent in the Catalan-speaking region of Spain) or toward the middle of the stressed syllable (prenuclear accent in at least some Caribbean varieties)», y $\mathrm{L}+\mathrm{H}^{*}$ como «early rising accent, with peak during the stressed syllable (Peninsular varieties) or just after the end of the stressed syllable if the syllable is intrinsically short (Caribbean varieties)». Pero véase Pilar Prieto, «The scaling of the $\mathbf{L}$ tone line in Spanish down-stepping contours», Joumal of Phonetics, 26, 1998, pags. 261-282. La tipología, en cualquier caso, es compleja, como se desprende de Ios trabajos de Eugenio Martínez Celdrán y Ana Ma. Fenández Planas, «Taxonomía de las estructuras entonativas de las modalidades declarativa e interrogativa del español estándar peninsular según el modelo $A M$ en habla de laboratorio», en E. Herrera y P. Martín, eds., op. cit., pp. 267-294, y Ana Ma. Fernández Planas y Eugenio Martínez Celdrán, «El tono fundamental y la duración: dos aspectos de la taxonomía prosódica en dos modalidades de habla (enunciativa e interrogativa) del español», Estudios de Fonética Experimental, 12, 2003, págs. 165-200. 
La diferencia entre las tres radica, como puede verse, en la forma elegida para marcar el escalonamiento ascendente (upstep) involucrado en la estructura circunfleja, un tono intermedio $\mathrm{H}$-, en el primer caso, un tono $\mathrm{H}$ precedente en el segundo, y un signo de admiración «i» en el tercero ${ }^{25}$. En cuanto a la primera notación, Hualde ha propuesto emplear $\mathrm{H}$ - como escalonamiento ascendente para representar el hecho de que «en español, en oraciones declarativas con estructura información conocida / información nueva, solemos encontrar una curva ascendente hasta el final de la parte del enunciado que representa información nueva» ${ }^{26}$. Quedarían así marcados de modo semejante tales casos de información nueva al final y los casos mexicanos. En estos, por otra parte, ha de examinarse todavía la manera en que se distribuye la información, pues el conocimiento del rendimiento discursivo y la génesis histórica de los materiales aquí analizados es todavía muy provisional ${ }^{27}$. Además, esta representación tendría la desventaja de ocupar el tono intermedio, que se va a usar aquí precisamente en uno de los varios patrones circunflejos, transcrito como $\mathrm{L}+\mathrm{iH}^{*} \mathrm{~L}$ $\mathrm{H} \%$, tal como se comentará más adelante ${ }^{28}$. La segunda solución parte del análisis de Sosa de ciertos ejemplos, en que el tonema $\mathrm{H}+\mathrm{H}^{*} \mathrm{~L} \%$ representa

la secuencia subyacente que proponemos para generar la configuración circunfleja alta propia de las interrogativas absolutas en el dialecto caraqueno, entre otros. El acento tonal nuclear $\mathrm{H}+\mathrm{H}^{*}$ tiene como efecto subir el tono de la última sílaba acentuada más de lo que normalmente habría subido con un tono $\mathrm{H}^{*}$ simple, por encima del cuerpo del grupo melódico. Como efecto de la altura alcanzada, el tono final $L \%$ no desciende hasta la línea de base, sino que queda como a medio camino ${ }^{29}$.

Beckman et al., por otra parte, sostienen el carácter algo abstracto de los acentos $\mathrm{L}+\mathrm{H}^{*} \mathrm{H}-\mathrm{y} \mathrm{H}+\mathrm{H}^{* 30}$. El tonema descrito por Sosa, por otra parte, se adscribe a interrogativas absolutas. Otra desventaja es que, en este trabajo, con

\footnotetext{
${ }^{25}$ Los signos «j" y «!» se emplean de manera convencional en el sistema de transcripción llamado "Tones and Break Indices» para marcar, respectivamente, los escalonamientos ascendentes y descendentes (cf. Beckman et al., op. cif.).

${ }^{26}$ «El modelo», op. cit., pág. 166. Cf. José Ignacio Hualde, «Intonation in Spanish and the other Ibero-Romance languages: overview and status quaestionis», en Romance Phonology and Variation, ed. C. Wiltshire y Joaquim Camps, Amsterdam, John Benjamins, 2002, págs. 101-116.

${ }^{27}$ En otro trabajo, en preparación en este momento, estoy considerando la proyección sintáctica y discursiva de las estructuras circunflejas, tomando en cuenta en particular el tipo de información aportada por el tonema (dada, nueva), el tipo de foco (amplio, estrecho, contrastivo), si se trata de la respuesta a una pregunta o apelación o no, si el enunciado es una apelación o no, la modalidad discursiva (narración, descripción, argumentación), así como la aportación global a la conversación.

${ }^{28}$ Patrón que, a su vez, seguramente admita representaciones alternativas.

29 Op. cil., págs. 121-122. Véanse también las págs. 123-125 y diversos pasajes del cap. 3. (págs. 204, 206-208, 227, quizá entre otras).

${ }^{30}$ Op. cit., págs. 26-27.
} 
esá notación se perdería la relación de aire de familia con otras estructuras interesantes de contorno circunflejo menos marcado.

Adopto por ahora, en consecuencia, la representación con el signo «j», para marcar el escalonamiento ascendente de los ejemplos mexicanos, simplemente como solución práctica a los propósitos, eminentemente descriptivos, de este trabajo ${ }^{31}$.

\section{ANÁLISIS DE DATOS}

Para el análisis que sigue aquí, se han considerado 180 ejemplos de enunciados declarativos de sentido completo, terminados todos en palabra llana. He tomado 10 ejemplos correlativos a partir, aproximadamente, del minuto 20 de grabación de una serie de entrevistas sociolinglísticas, de cada uno de 18 informantes de nivel sociocultural bajo, que por lo regular va equivaliendo a estudios de primaria o menos, distribuidos en nueve hombres y nueve mujeres, y seis personas de cada uno de tres segmentos de edad: de 20 a 34 , de 35 a 54 y de 55 en adelante, todos ellos procedentes del proyecto de «Cambio y variación lingüística en la ciudad de Méxicon, que se viene desarrollando en El Colegio de México desde hace algunos años.

Como variable dependiente tomo la transcripción tonal de la curva melódica, en los siguientes términos:

\section{Patrones tonales}

Patrón A (64 casos, 35.5\%): $\mathrm{L}+\mathrm{H}^{*} \mathrm{~L} \%$

PATRÓN B (56 casos, 31.1\%): L+H* L\%

PATRÓN C (19 casos, 10.5\%): con tono intermedio, sobre todo $\mathrm{L}+\mathrm{j} \mathrm{H}^{*} \mathrm{~L}-\mathrm{H} \%$

PATRON D (12 casos, $6.6 \%)$ : otros patrones con $\mathrm{L}+\mathrm{H}^{*}$ o $\mathrm{L}+\mathrm{jH}^{*}$

PATRON Z (29 casos, 16.1\%): otros patrones, muchos de ellos L* L\%

Lo que quieren decir estos patrones de transcripción es, básicamente, una combinación de factores acústicos y perceptuales. Los aspectos fónicos que he considerado en cada ejemplo son los que siguen.

$F_{0}$ inicial (en hertzios, $\mathrm{Hz}$ ). $-\mathrm{F}_{0}$ máximo $(\mathrm{Hz})-\mathrm{F}_{0}$ mínimo $(\mathrm{Hz})$ - Campo tonal (en semitonos, st). $-\mathrm{F}_{0}$ de la sílaba pretónica $(\mathrm{Hz}) .-\mathrm{F}_{0}$ de la sílaba tónica.-Movimiento tonal de la pretónica a la tónica (st).- $\mathrm{F}_{0}$ del tono intermedio, si lo hay $(\mathrm{Hz})$.- Movimiento tonal de la sílaba tónica al tono intermedio (st).- $\mathrm{F}_{0}$ de la silaba postónica (Hz).-Movimiento tonal de la sílaba tónica a la postónica (st)--Movimiento tonal del tono intermedio a la postónica (st).-Duración de la silaba tónica (en milisegundos, ms).-Duración de la sílaba postónica (ms).-Duración del tonema (ms).- - Velocidad de

3! Puede encontrarse una discusión detallada de los escalonamientos ascendentes, su representación y su dominio de aplicación en las págs. 22-31 del trabajo ya citado de Beckman et al. 
los movimientos tonales (st/ms). - Sílaba en que se sitúa el pico tonal del final del enunciado (pretónica, tónica, postónica).-..Parte de la silaba en que se sitúa el pico tonal (comienzo, medio, final).

Las mediciones de frecuencia en $\mathrm{Hz}$ y de la duración en ms se han llevado a cabo por medio del programa Pitchworks, refrendadas en muchos casos por medio del programa Praat ${ }^{32}$. Las mediciones en semitonos son útiles para reducir a una sola escala diferencias tonales como las que existen entre hombres y mujeres; además, se ha propuesto que sólo movimientos tonales superiores a más de 1.5 semitonos tendrían valor lingüístico ${ }^{33}$. Para calcular los semitonos se emplea la siguiente fórmula ${ }^{34}$ :

$\left(12 /\right.$ LOG10(2)) $\times\left(\right.$ LOG $10\left(F_{0}\right.$ de la primera medición $/ F_{0}$ de la segunda medjcion))

Analizo en primer término los resultados generales según se fueron presentando para cada uno de los patrones.

PATRón A (64 CASOS, 35.5\%): L+jH* L\%

Los casos incluidos bajo este primer patrón, el A, son los que más prototípicamente corresponden a la estructura circunfleja tal como se presenta de modo específico en la ciudad de México. Más allá de la impresión perceptual, la expectativa es que acústicamente se caractericen por un fuerte ascenso tonal en la silaba tónica, seguido por un descenso en la postónica, así como un alargamiento general de todo el tonema. Veamos en qué medida se cumple esta expectativa. Para ello, empiezo analizando por separado $\mathrm{los} 64$ casos etiquetados con la estructura $\mathrm{L}+\mathrm{i} \mathrm{H}^{*}$ L\%, y más adelante se intentará ver cuáles son las diferencias acústicas que el patrón mantiene con respecto a otros movimientos melódicos. He aquí algunos ejemplos con el patrón circumflejo más característico:

${ }^{32}$ Pitchworks 4.4 (Encino, Scicon R\&D, 1999, www.sciconrd.com); Praat 4.2.06 (Paul Boersma y David Weenink, Amsterdan, Institute of Phonetic Sciences, 2004, www fon.hum.uva.n//praat).

33 Cf. Martínez Celdrán y Fernández Planas, «Taxonomía», op. cit., en especial las págs. 291-293.

34 Sieb Nooteboom, «Prosody of speech: melody and thythm», en The Handbook of Phonetic Sciences, ed. W. J. Hardcastle y John Laver, Oxford, Blackwell, 1997, pág. 645. 
[en ra tos]

$\mathrm{L}+\mathrm{i} \mathrm{H}^{*} \mathrm{~L} \%$

(Florencio M., ME-127-11H-01, CD-1, Pista 5)

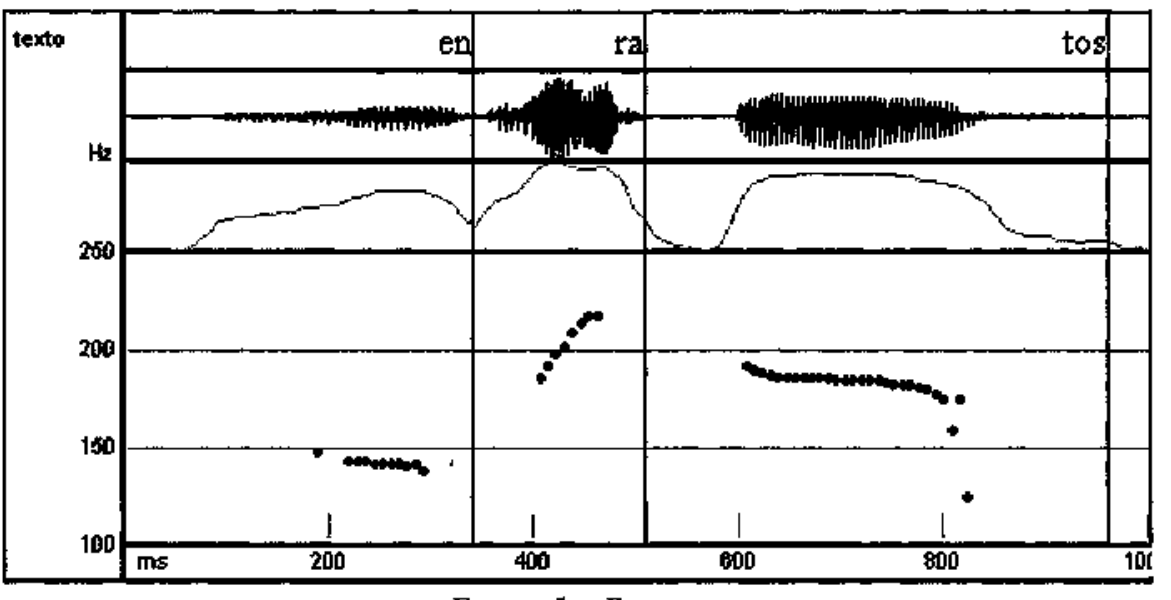

FIGURA 5.-En ratos.

[él cuidaba igual ca ba llos]

$$
\mathbf{L}+\mathbf{i} \mathbf{H}^{*} \mathbf{L} \%
$$

(Felipa G., ME-051-11M-99, CD-1, Pista 5)

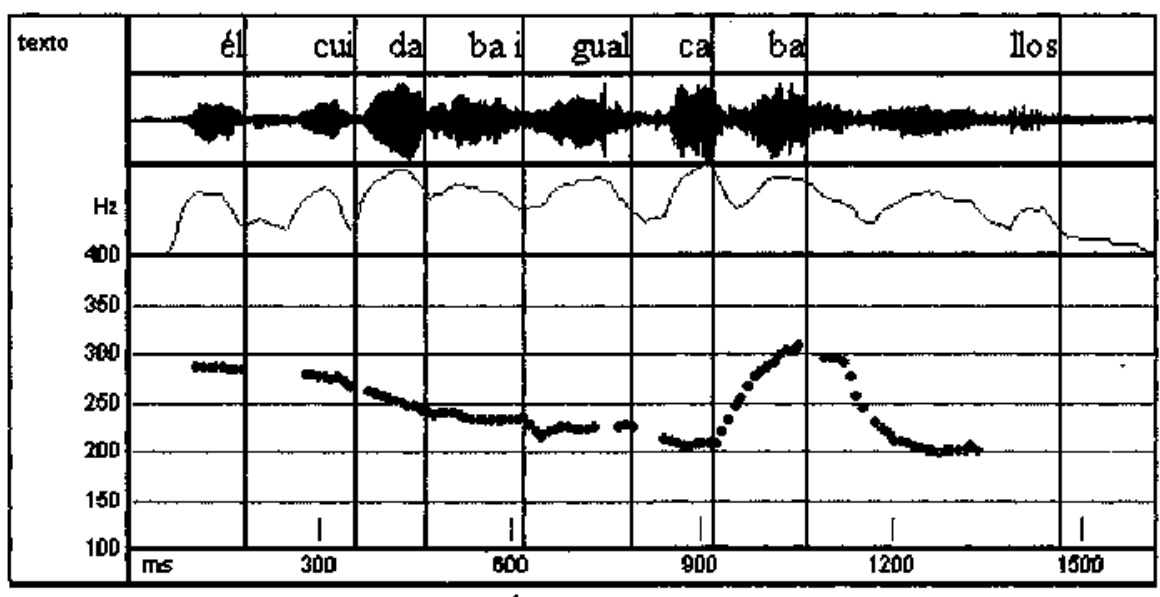

FIGURA 6.-Él cuidaba igual caballos. 
[pues no hago ningún ejercicio de que mueva yo el] [el nervio]

(Cristobalina R., ME-129-12M-01, CD-1, Pista 5)

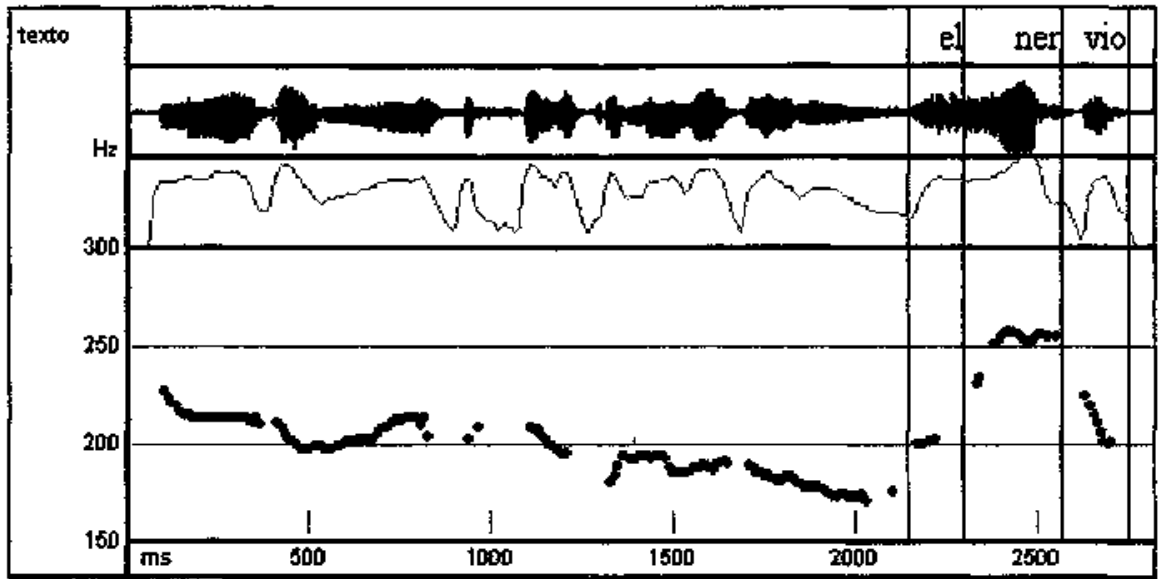

FIGURA 7.-Pues no hago ningún ejercicio de que mueva yo el el nervio.

El campo tonal promedio en semitonos de los 64 casos es de 7.36 st. Lo más importante ahora, con todo, son los movimientos en el tonema. En promedio, hay un movimiento ascendente de 4.52 semitonos de la sílaba pretónica a la tónica, con 2.90 de desviación estándar, y descendente de 12 semitonos de la tónica a la postónica. Ahora bien, en 6 casos la postónica resultó completamente ensordecida, y se asigno un valor convencional de 1 a su altura melódica para poder efectuar los cálculos generales. Suprimidos estos 6 casos, que naturalmente provocan unas diferencias mucho mayores a lo habitual, el promedio en semitonos de los otros 58 casos es un descenso de 3.42 st, con 2.61 de desviación estándar, que es el que tomo para disponer el prototipo acústico del patron $\mathrm{L}+{ }_{i} \mathrm{H}^{*} \mathrm{~L} \%$. La velocidad de ascenso en el tramo $\mathrm{L}+\mathrm{iH}^{*}$ es mayor $(0.0227 \mathrm{st} / \mathrm{ms})$ que en el tramo de descenso $(0.0162 \mathrm{st} / \mathrm{ms})$. En términos de frecuencia en hertzios, estas cantidades globales en semitonos suponen para los hombres un ascenso promedio de $35 \mathrm{~Hz}$ y un descenso promedio de $27 \mathrm{~Hz}$; para mujeres, el promedio de ascenso es $69 \mathrm{~Hz}$ y el de descenso $92 \mathrm{~Hz}$.

En cuanto a la duración de las sílabas, la sílaba tónica dura en promedio $198.8 \mathrm{~ms}(\sigma=53.3)$ y la postónica $210.8 \mathrm{~ms}(\sigma=105.3)$; en conjunto, y considerando la relación entre tónica y postónica en cada uno de los ejemplos, esta última es 1.12 veces más larga que la tónica $(\sigma=0.65)$. En cuanto a la longitud del tonema, tomada como la suma de tónica y postónica, es en promedio de $409.6 \mathrm{~ms}(\sigma=125.5)$. 


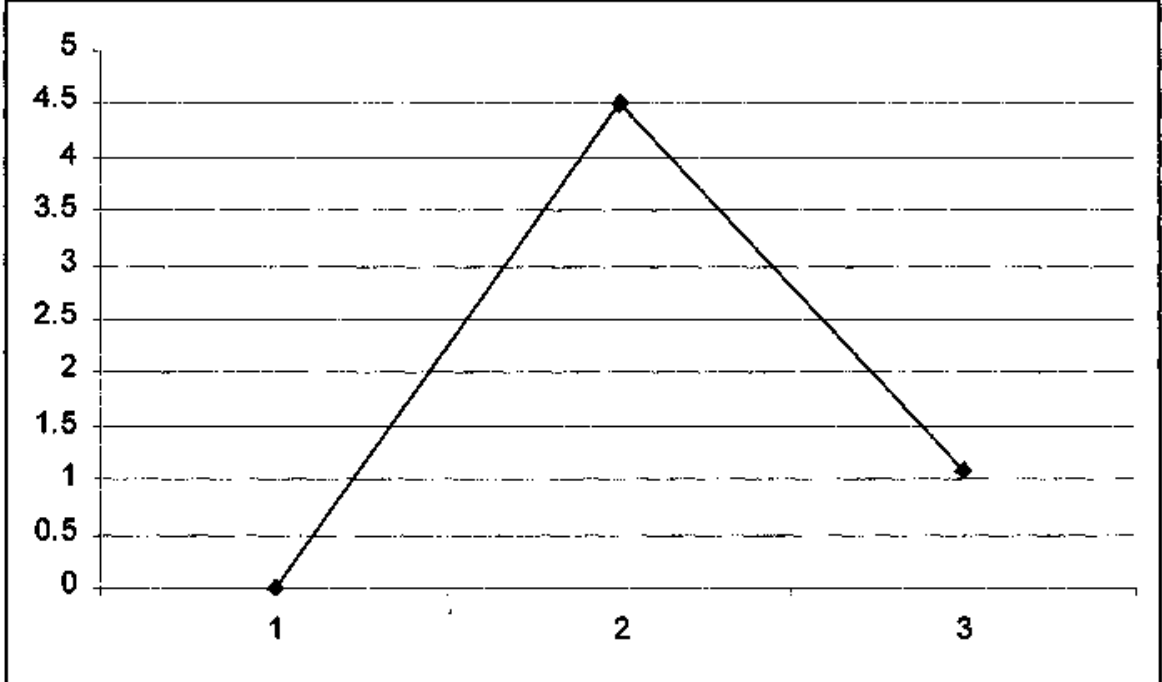

Figura 8.-Movimientos tonales (en st) para el patrón $\mathrm{L}+{ }_{i} \mathrm{H}^{*} \mathrm{~L} \%$; el segmento $1-2$ corresponde a la sílaba tónica, el 2-3 a la postónica.

Sólo dos casos presentaron el pico tonal en la postónica, el resto, 62 de 64 , lo que vale decir casi todos los casos $(\mathrm{f}=0.969)$, presentaron el pico tonal en la síaba tónica. De estos 62 casos, una notable mayoría presentó el pico en la parte final de la silaba tónica ( 46 casos, $f=0.742$ ), aunque hubo una cantidad interesante de casos que presentó el pico en la parte media de la sílaba (12 casos, $\mathrm{f}=0.194$ ) y muy pocos en realidad en el comienzo de la silaba tónica (sólo 4 casos, $\mathrm{f}=0.065)^{35}$.

En cuanto a los factores sociales para estos informantes del nivel bajo, de momento las diferencias son prácticamente nulas en cuanto a edad y sexo. Hombres y mujeres se reparten a cantidades exactamente iguales (32 y 32 ) estos 64 casos, y por edades la diferencia es insignificante: 20 en la generación más joven, 21 en la intermedia y 23 en las personas de más edad.

\section{PATRÓN B (56 CASOS, 31.1\%): L+H* L\%}

Los casos incluidos en este segundo subgrupo presentan subidas tonales perceptualmente claras, pero no parecen diferentes en sí mismas a las que se

${ }^{35}$ Las proporciones disminuyen ligeramente al considerar los 64 casos catalogados en el patrón: 0.719 con pico en la parte final de la tónica, 0.188 en la media y 0.024 en la inicial. De los 2 casos con pico en la postónica, 1 presentó el pico al comienzo y $l$ al final. 
han mencionado para otros dialectos del español cuando llega a presentarse el patrón circunflejo en enunciados declarativos. La expectativa es que las subidas tonales no sean ahora tan marcadas como con el Patrón A, y que la duración del tonema se reduzca también un poco con respecto a los casos anteriores. He aquí un ejemplo característico:

\section{[si] [siempre the estado con ellas]

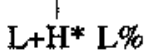

(Carmen M., ME-053-11M-00, CD-1, Pista 5)

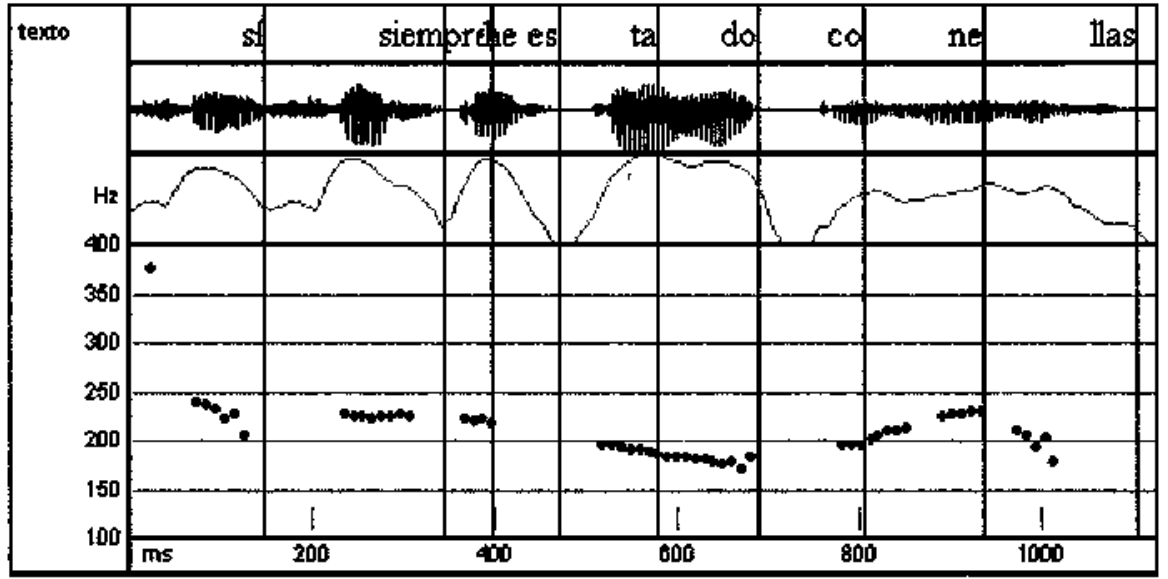

FIGURA 9.-Si siempre he estado con ellas.

El campo tonal promedio de los 56 casos es 7.65 st, muy semejante, como era de esperarse en realidad, al del Patrón A (7.36 st). El movimiento tonal ascendente de la pretónica a la tónica es, igualmente en promedio, de 2.65 st $(\sigma=2.86)$. Este es un resultado interesante, porque es bastante menos pronunciado al que aparecía en el caso A, en el que el ascenso llega a 4.52 st. De alguna forma, este hecho es un argumento a favor de la idea de analizar los primeros casos como $\mathrm{L}+\mathrm{j} \mathrm{H}^{*}$, y estos segundos como $\mathrm{L}+\mathrm{H}^{*}$. El movimiento descendente es en general de 23.03 st, alto en realidad por el peso de los finales ensordecidos. De hecho, es llamativo que en este caso hubiera 12 de 56 casos ensordecidos, $(f=0.214)$, frente a 6 de 64 en $A(f=0.093)$, lo que está sugiriendo una mucho menor concentración de energía en el tonema en $B$, o lo que es lo mismo, una mayor concentración de energía en A. Suprimidos estos 12 casos del cálculo del movimiento tonal descendente, el descenso promedio es de 3.95 st $(\sigma=4.26)$, que aunque es ligeramente mayor al encontrado en $A$ (3.42 st), sugiere que en ambos casos el descenso se está realizando básica- 
mente en los mismos términos, lo que a su vez apoya la idea de marcar como L\% ambos casos. La velocidad de ascenso es de $0.0152 \mathrm{st} / \mathrm{ms}$, y la de descenso 0.0229 , lo que, en comparación con el Patrón A, supone que en B se asciende más lentamente pero se desciende con mayor velocidad. En hertzios, los hombres ascienden en $\mathrm{B}$ un promedio de $19 \mathrm{~Hz}$ y descienden $24 \mathrm{~Hz}$, y las mujeres suben $31 \mathrm{~Hz}$ y bajan $46 \mathrm{~Hz}$.
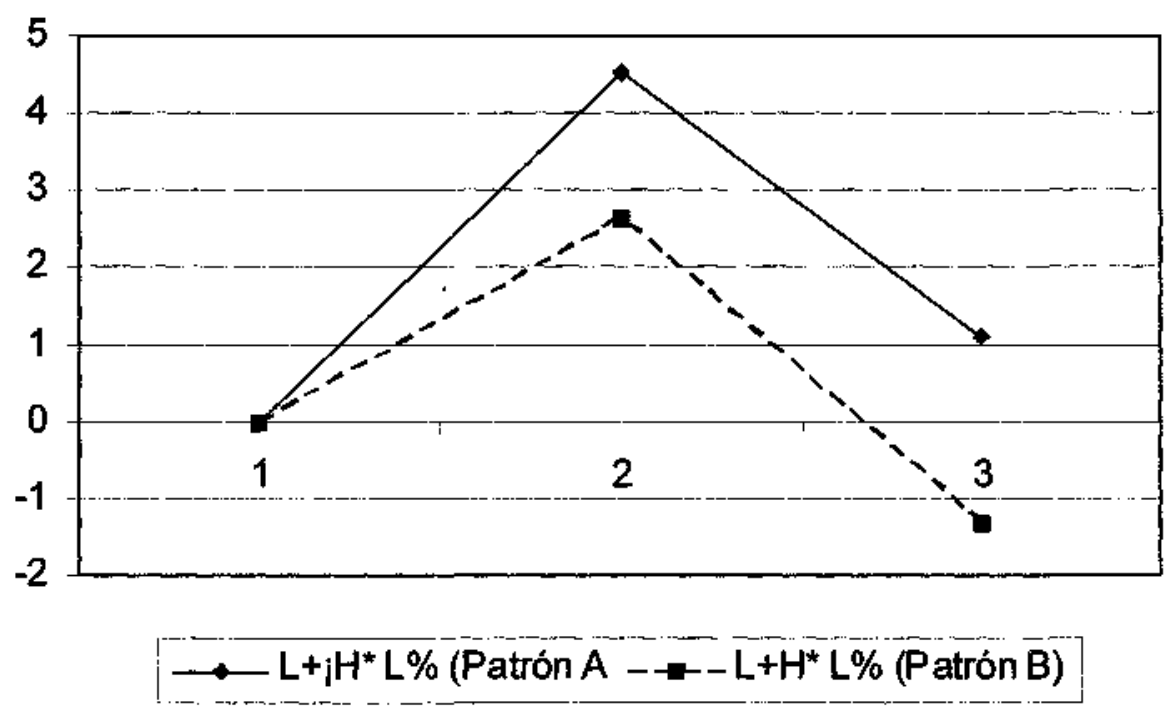

Figura 10.-Comparación de los movimientos tonales, en st, de los Patrones A y B; el segmento 1-2 corresponde a la silaba tónica, el 2-3 a la postónica.

En cuanto a las medidas de duración, el promedio de la tónica es de $\mathbf{1 7 3 . 9}$ $\mathrm{ms}(\sigma=57.7)$, y el de la postónica $172.8 \mathrm{~ms}(\sigma=74)$; la duración del tonema es $346.8 \mathrm{~ms}(\sigma=90.4)$. En el promedio de los ejemplos considerados uno a uno, la postónica es 1.13 veces más larga que la tónica $(\sigma=0.67)$. Hay varios aspectos interesantes en estos resultados. En el Patrón B, las dos sílabas y desde luego el tonema en su conjunto es más breve que en el patrón A (allí la tónica duraba, como se ha dicho, $198.8 \mathrm{~ms}$, la postónica $210.8 \mathrm{~ms}$ y el tonema $409.6 \mathrm{~ms}$ ). La sîlaba tónica del Patrón A dura 1.14 veces más que la de B, la postónica de A dura 1.21 veces más que la de $\mathrm{B}$ y el tonema dura en $\mathrm{A} 1.18$ veces más que en B. Por otra parte, la relación entre tónica y postónica es en ambos casos enteramente igual: considerados los casos uno a uno, en A las postónicas son 1.12 veces más largas que las tónicas, y en $\mathrm{B} 1.13$ veces más largas. Lo que esto quiere decir, me parece, es que la diferencia entre A y B se manifiesta en 
la duración absoluta de cada una de las síabas, mientras que la duración relativa entre ellas es una propiedad compartida.

De los 56 casos, 54 presentaron el pico tonal en la tónica $(f=0.964)^{36}$. De estos 54 enunciados, 26 presentaron el pico en la parte final de la síaba ( $\mathrm{f}=0.481), 23$ en el medio $(0.425)$ y sólo 5 ( $\mathrm{f}=0.065)$ en la parte inicial. Supone esto una diferencia de alineamiento del pico tonal dentro de la silaba con respecto a lo que ocurría en A. En A, el predominio del pico en la parte final era mucho más claro ( 0.742 de los casos), y el pico en la parte central se asignaba a un porcentaje no despreciable $(0.194)$, pero en modo alguno tan sustancial como el de B. De alguna forma, lo que ocurría en A es que el ascenso tendía a prolongarse hasta el final de la sílaba, lo que está a su vez unido a la idea del mayor ascenso tonal que se produce en A. Hay, pues, tres diferencias entre ambos casos, vinculadas entre sí: la amplitud del ascenso tonal, la duración del tonema y las tendencias en la alineación de los picos en la síaba tónica.

En cuanto a los factores sociales, hombres y mujeres se repartieron casi equitativamente este segundo patrón (29 casos los hombres y 27 las mujeres), y aunque hay diferencias por generaciones ( 15 casos la primera, 23 la segunda y 18 la tercera), no parece claro que la distribución esté siguiendo ningún patrón específico.

PATRÓN C (19 CASOS, 10.5\%): CON TONO INTERMEDIO, SOBRE TODO $\mathrm{L} \mathrm{iH}^{*}$ L- H\%

Este es uno de los patrones más interesantes, por los usos melódicos desarrollados en él -parece necesario postular un tono intermedio-m y por sus repercusiones sociolinguísticas. En sus formas más exageradas llega a convertirse en un estereotipo, y en general su uso parece estar estratificado socialmente (lo que será necesario confirmar) y es más usado por hombres (como se verá en un instante). Acústicamente, se caracteriza por presentar un nuevo tramo de ascenso melódico, después de haberse emprenđido el descenso, lo cual se reconoce perceptualmente con bastante claridad. Considérese en primer término un par de ejemplos:

\footnotetext{
${ }^{36}$ Hubo un ejemplo con pico en la pretónica y otro en la postónica.
} 


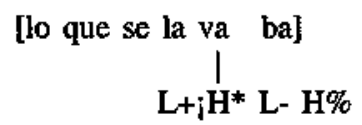

(Simón R., ME-222-11H-02, CD-1, pista 5)

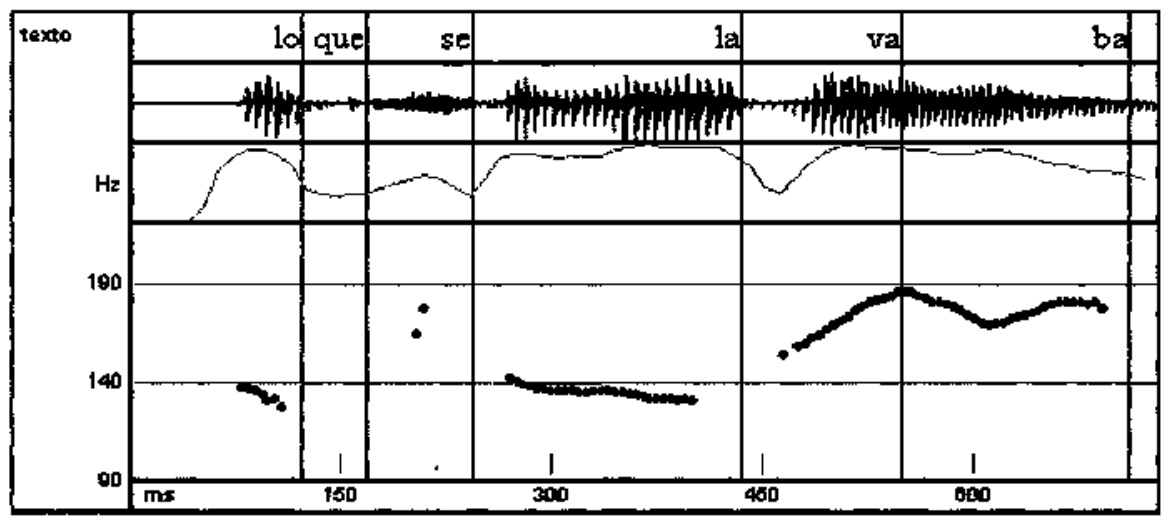

Figura 11.-Lo que se lavaba.

Como puede verse, este ejemplo, Lo que se lavaba, con estructura $\mathrm{L}+\mathrm{j}^{\mathrm{H}} \mathrm{H}^{*}$ L- $\mathrm{H} \%$ presenta una clara subida a lo largo de la sílaba $v a$, y luego un descenso en la primera parte de la silaba $b a$, representado por el tono intermedio $\mathrm{L}$, lo que da el patrón circunflejo básico $\mathrm{L}$ ¡ $\mathrm{H} \mathrm{L} \mathrm{y}$, por último, en la segunda parte de la sílaba, un nuevo ascenso, representado aquí como $\mathrm{H} \%$. El ejemplo presenta incluso un pequeño descenso al final: la parte final parece casi un «eco» melódico. Muy parecido es el caso siguiente:

[sí] [no] [bas tante]

$\mathrm{L}+\mathrm{i} \mathrm{H}^{*} \mathrm{~L}-\mathrm{H} \%$

(Felipe J., ME-131-13H-01, CD-1, Pista 5)

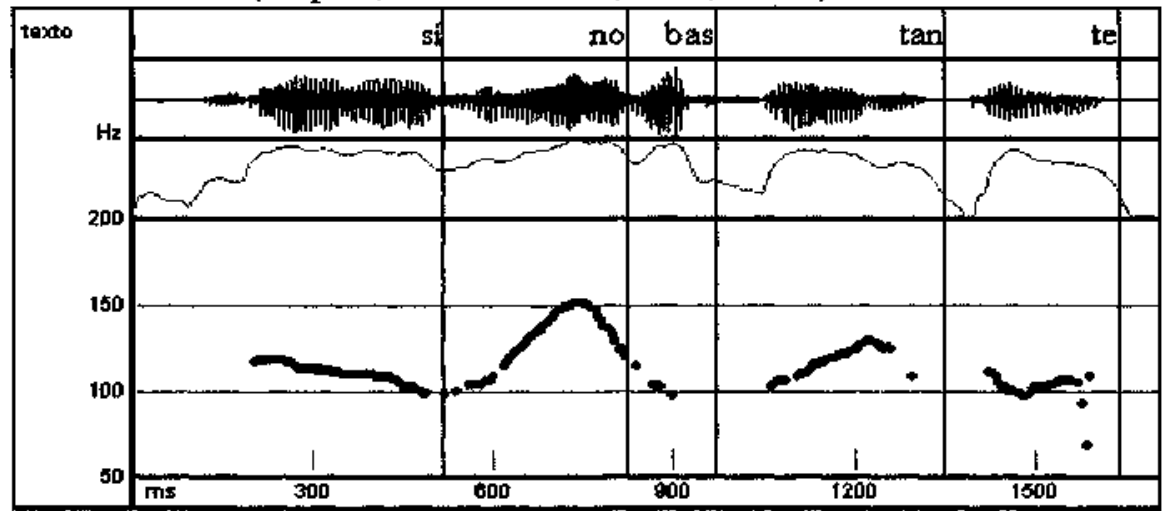

FIGURA 12.-SI no bastante. 
El promedio del campo tonal para el subgrupo es $7.46 \mathrm{st}$, muy semejante a lo visto con los patrones A y B, que era precisamente lo que se esperaba. De los 19 casos para los que se postula un tono intermedio, 15 se describen como $\mathrm{L}+\mathrm{jH}^{*} \mathrm{~L}-\mathrm{H} \%$. En todos, menos en un caso, se propone como tono nuclear $\mathrm{L}+\mathrm{jH}^{*}$; el único caso en que no, supone una estructura $\mathrm{L}^{*}+\mathrm{H}$, que en líneas generales no afecta demasiado a la composición ascendente del patron. El promedio ascendente de todos los casos es de $4 \mathrm{st}, \sigma=2.37$ (4.11 sin considerar el ejemplo con $\mathrm{L}^{*}+\mathrm{H}$ ), lo que deja al patrón $\mathrm{C}$ más cerca del patrón $\mathrm{A}-$ de 4.52

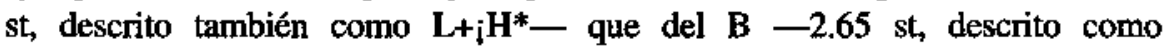
$\mathrm{L}+\mathrm{H}^{*}$ - En 18 de los 19 casos se postula un tono intermedio bajo, L-, para los que el promedio de descenso es de $3.52 \mathrm{st}(\sigma=2.37)$. Este promedio es muy cercano al encontrado en los otros dos patrones ya examinados (3.42 en A y 3.95 en B), lo que permite incluir también la mayor parte de los casos de C en la familia circunfleja. Por fin, 16 de los 19 casos terminan en un tono de juntura ascendente, con un promedio de 2.22 st de ascenso, aunque con gran variación en los datos, lo que se refleja en la alta desviación estándar $(\sigma=3.21)^{37}$. En promedio, los hombres ascienden $31 \mathrm{~Hz}$, descienden 26 y vuelven a ascender $20 \mathrm{~Hz}$. Las mujeres ascienden $69 \mathrm{~Hz}$, descienden 61 y se elevan al final (en los pocos casos en que se trata de mujeres) otros $14 \mathrm{~Hz}$. En esquema el patrón $\mathrm{C}$ tiene esta forma ${ }^{38}$ :

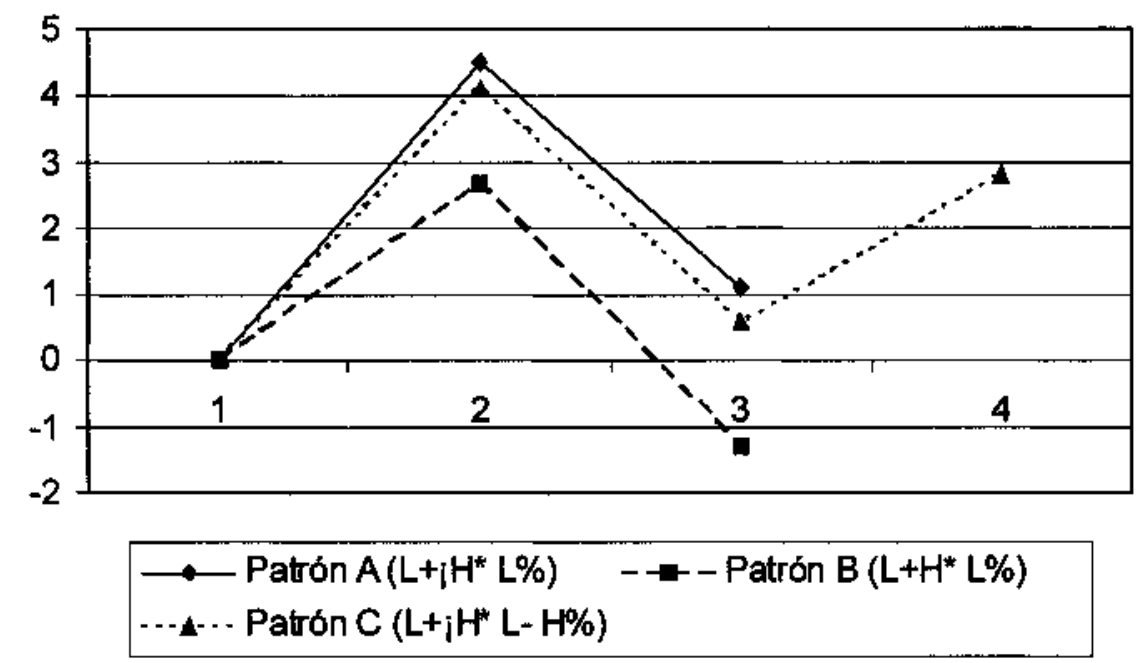

FIGURA 13. - Esquema en st de los movimientos melódicos del patron $\mathrm{L}+\mathrm{i}_{\mathrm{i}} \mathrm{H}^{*} \mathrm{~L}-\mathrm{H} \%$, en comparación con los Patrones A y B; el segmento 1-2 corresponde a la sílaba tónica, 2-4 a la postónica.

\footnotetext{
${ }^{37}$ Se postulan dos casos de L\% y uno de M\%.

${ }^{38} \mathrm{La}$ velocidad ascendente es de $0.0199 \mathrm{st} / \mathrm{ms}$. No he calculado la velocidad de los movimientos asociados a $\mathrm{L}-\mathrm{y} \mathrm{H} \%$.
} 
Como puede verse en la figura 13, el patrón $\mathrm{C}$ es casi idéntico en sus dos primeros movimientos al patrón $\mathrm{A}$, lo que apoya la idea de etiquetar el acento tonal nuclear de ambos casos como $\mathrm{L}+\mathrm{i} \mathrm{H}^{*}$.

La duración de las sílabas de los ejemplos del patrón $\mathrm{C}$ es también muy reveladora. La slaba tónica mide en promedio $200.4 \mathrm{~ms}(\sigma=83.7)$, muy semejante a la de A (198.8 ms), y bastante más larga que la de B (173.9 ms). Muy llamativas son las diferencias en la duración de la postónica. Como era de esperarse, dados los movimientos tonales complejos que los casos de $\mathrm{C}$ exhiben en la sílaba postónica, esta es bastante larga, de $264.3 \mathrm{~ms}$ en promedio $(\sigma=83.2)$, frente a las sílabas de A $(210.8)$ y B $(172.8 \mathrm{~ms})$. Esto da pie al tonema más largo, de $464.7 \mathrm{~ms}$ en $\mathrm{C}, \sigma=135$ (frente a los 409.6 de A y 346.8 de B). Por fin, si la relación entre la postónica y la tónica era muy semejante en A y B (1.12 y 1.13), en C la postónica es mucho más larga que la tónica, de hecho 1.53 veces mayor $(\sigma=0.95)$ al considerar caso por caso.

Todos los ejemplos, salvo uno (el del patrón $\mathrm{L}^{*}+\mathrm{H}$ ), mostraron el pico en la sílaba tónica $(\mathrm{f}=0.947)$. De esos 18,12 mostraron el pico de tonicidad al final de la sílaba tónica, y 6 en la parte media.

En cuanto a los factores sociolinguísticos, las diferencias entre hombres y mujeres son, de entrada, bastante llamativas, pues 14 de los 19 ejemplos fueron producidos por hombres. No hay, en principio, un patron claro por generaciones: 9 ejemplos la primera, 4 la segunda, 6 la tercera. Aunque no puedo confirmarlo porque se trata de muy pocos datos, el patrón $\mathrm{C}$ parece llegar a perfiles más extremos en el caso de los hombres. Si se analizan solos los 11 ejemplos de patron $\mathrm{L}+\mathrm{iH}^{*} \mathrm{~L}-\mathrm{H} \%$ producidos por hombres, los resultados son llamativos. Aunque los movimientos melódicos correspondientes al acento nuclear son normales (3.94 st de subida y 3.59 de bajada), el ascenso en el $\mathrm{H} \%$ alcanza los 2.86 st (frente al 2.22 del promedio general de C), y la sílaba postónica alcanza los $281 \mathrm{~ms}$ (frente a los 264.3 de promedio de C) y el tonema 487.34 $\mathrm{ms}$ (464.7 el promedio). Es decir, en la sílaba postónica los hombres ascienden un $28.8 \%$ más que el promedio, y esta misma sílaba dura $6.3 \%$ más que el promedio.

PATRONES D (12 casos, $6.6 \%$ ): otros patrones con $\mathrm{L}+\mathrm{H}^{*}$ o $\mathrm{L}+\mathrm{j} \mathrm{H}^{*}$ y $\mathrm{Z}$ (29 casos, 16.1\%): otros patrones, muchos de ellos $\mathrm{L}^{*} \mathrm{~L} \%$

Voy a referirme brevemente al resto de los casos. Los casos etiquetados como patrón D poseen acentos nucleares $\mathrm{L}+\mathrm{H}^{*}$ y $\mathrm{L}+\mathrm{j} \mathrm{H}^{*}$, pero no se perciben como circunflejos, o sólo muy vagamente, porque en todos los casos terminan en un tono de juntura medio $\mathrm{M} \%$ o alto $\mathrm{H} \%$. Presentan una subida promedio significativa pero menor a la de los patrones más claramente circunflejos: 
3.12 st $(\sigma=2.26)$. El tramo final es muy variable $(\sigma=0.91)$, con pequeños descensos, algunos ascensos y muchos mantenimientos, y se salda en promedio en 0.47 st en dirección ascendente, cantidad que puede no ser significativa melódicamente, en particular si se acepta la idea del umbral de 1.5 st. En cuanto a la duración del tonema, queda en los parámetros normales: $384.85 \mathrm{~ms}(\sigma=77.3)$.

Por fin, en el conjunto $Z$ se han agrupado el resto de los casos, que ofrecen soluciones variadas. Sin embargo, la inmensa mayoría, 27 de 29 , muestran un tono nuclear bajo $L^{*}(\mathrm{f}=0.931)$ y la mayoría el patrón tonemático $L^{*} \mathrm{~L} \%, 18$ de 29 ( $\mathrm{f}=0.620$ ). El promedio de descenso en los que tienen un patrón descendente es de 2.15 st de la pretónica a la tónica, y de 2.42 st de la tónica a la postónica (una vez excluidos los casos. de finales ensordecidos). El ejemplo siguiente muestra uno de los casos incluidos entre los más prototípicos del subgrupo Z:

[bueno yo no conozco nada de Zacatecas]

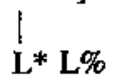

(Francisca M., ME-219-12M-02, CD-1, Pista 5)

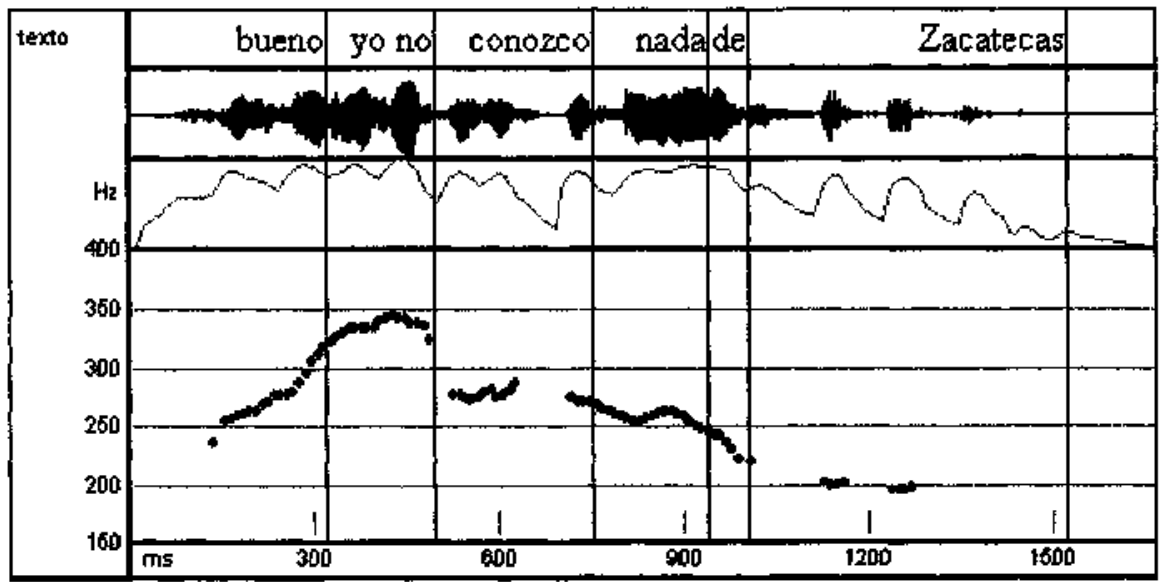

FIGURA 14.-Bueno yo no conozco nada de Zacatecas.

\section{OTROS ASPECTOS}

Aunque este trabajo sólo se ocupa de las declarativas no continuativas terminadas en palabras llanas, el patrón circunflejo aparece tanto con finales no llanos como en secciones continuativas intermedias. La cuestión merece estudiarse en detalle, y aquí me limito a incluir algunos ejemplos. 
a) Patrones circunflejos en finales agudos y esdrujulos

El primer ejemplo ofrece movimientos circunflejos (Patrones A y B) con palabras agudas, y el segundo presenta un caso con una palabra esdrújula (Patrón B):

[que dice no::] [y es que me va a dejar peor] [le digo no:]

$$
\mathrm{L}+\mathrm{j} \mathrm{H}^{*} \mathrm{~L}-
$$

L* L

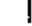

(Cristobalina R., ME-129-12M-01, CD-1, Pista 5)

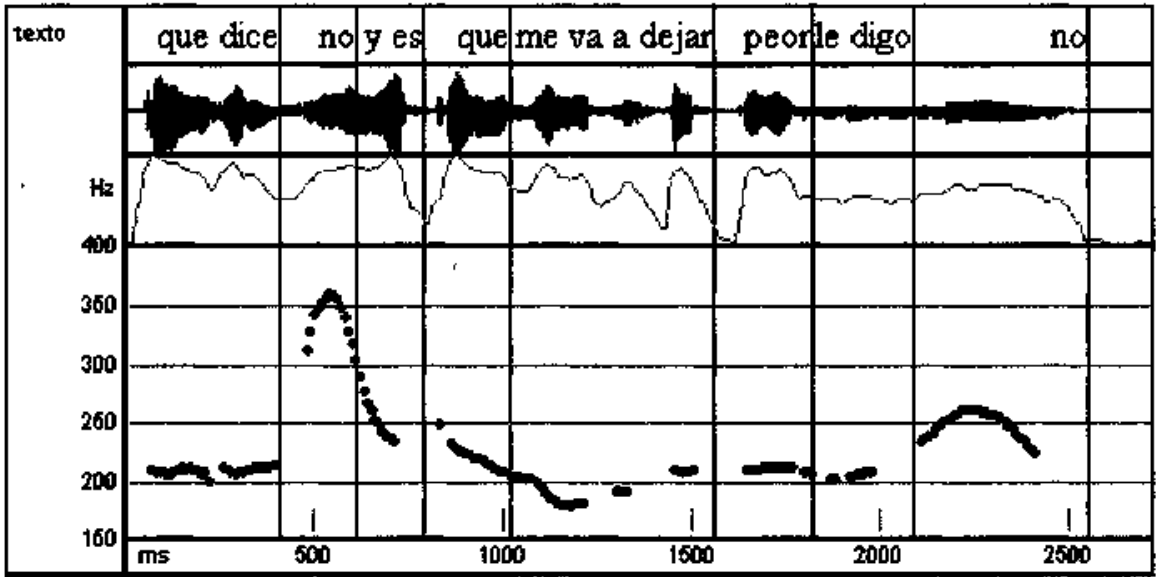

FIgURA 15.-Que dice no y es que me va a dejar peor le digo no.

[pa que nos váyamos]

$\mathbf{L}+\mathbf{H}^{*} \mathbf{L} \%$

(Espiridión P., ME-113-13H-01, CD-1, Pista 5)

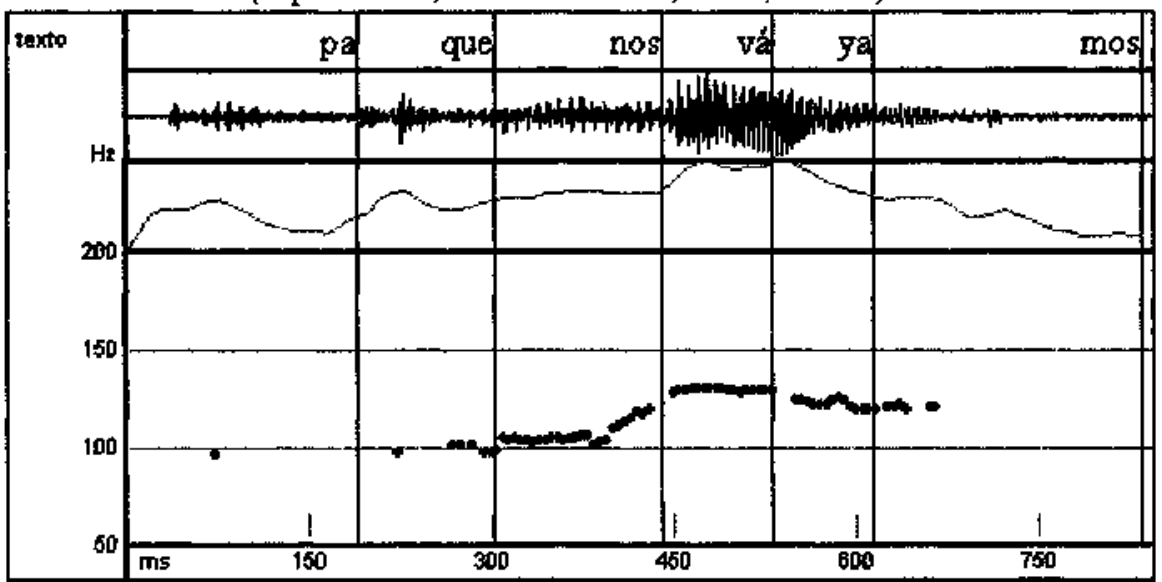

FIGURA 16.-Pa que nos váyamos. 
La expectativa es que los movimientos tonales sean semejantes, pero extendidos en períodos temporales más breves o más largos, según el tipo acentual de la palabra final.

\section{b) Movimientos circunflejos no finales de enunciado}

Esta cuestion es de gran interés, y habla de las fntimas relaciones entre entonación y discurso. De nuevo es algo de lo que no me he ocupado en este trabajo, pero que merecerá ser examinado después con antención.

[pues era bastante este] [maíz]<smiles>[Tl]</smiles>

$\mathrm{L}+\mathrm{j} \mathrm{H}^{*} \mathrm{~L}-$

(Simón R., ME-222-11H-02, CD-1, pista 5)

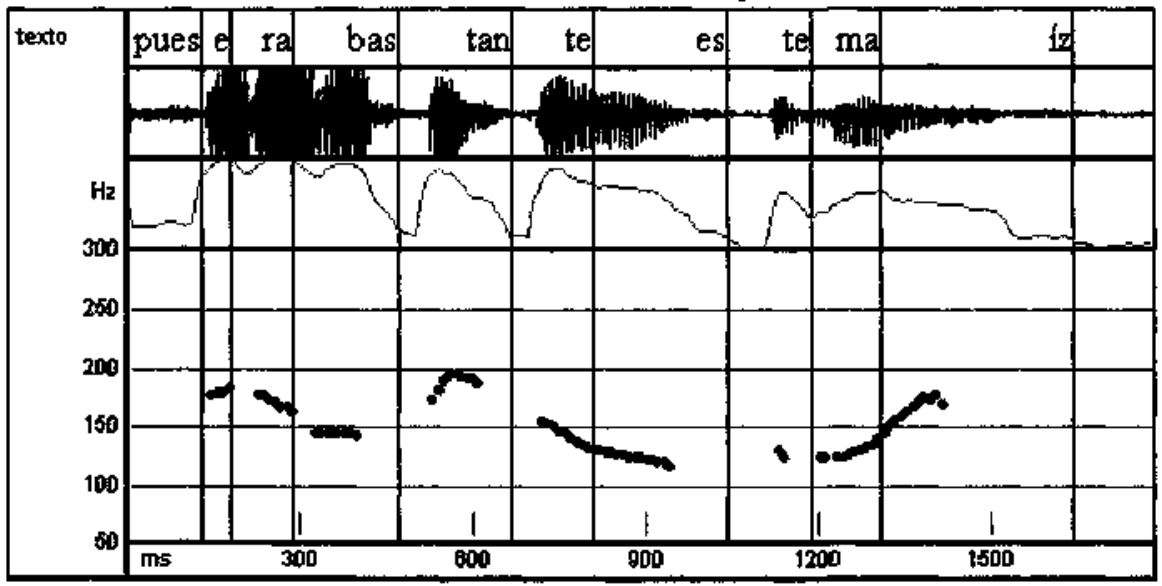

FIGURA 17-Pues era bastante este maí

En el ejemplo anterior, la síaba tan alcanza un notorio pico tonal, que luego adopta un camino descendente hasta el final de la frase entonativa (por cierto, con patrón circunflejo también en la palabra aguda matz en el final no continuativo). El siguiente caso sugiere una pregunta interesante: 


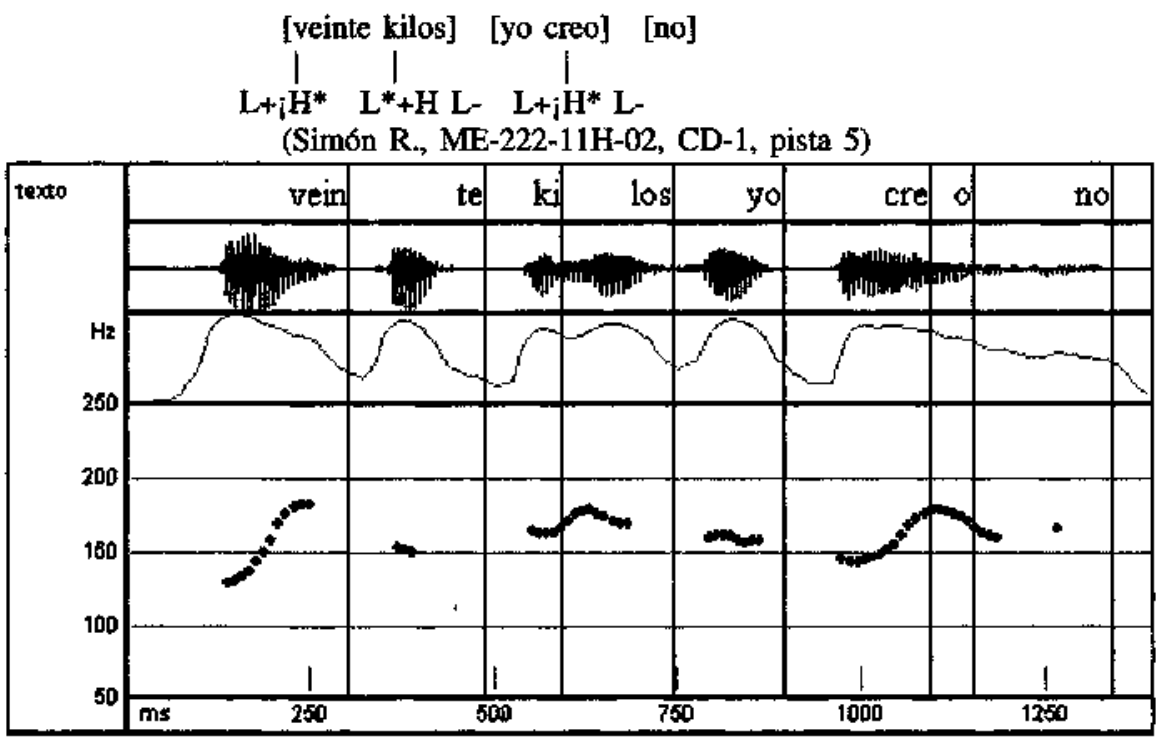

FIGURA 18.-Veinte kilos yo creo no.

Simón $\mathbf{R}$. introduce en este ejemplo dos patrones circunflejos, uno en vein$t e$, en apariencia en posición focal, y otro en el tonema de la frase intermedia yo creo. Una cuestion interesante es si algunos hablantes aplican una estrategia de generalización del acento circunflejo, que de menos a más abarcaría los siguientes contextos:

Tonema de declarativa no continuativa

Final de frase intermedia

Cualquier acento

Por otra parte, el paralelismo entre el tramo no continuativo de la declarativa y la frase intermedia puede llegar a ser bastante grande, como ocurre en la figura 19, aunque aquí quepa interpretar también [a encontrarme]\% [o sea traerme]\%, es decir, con dos terminaciones, donde la segunda es una ampliación o aclaración de la primera: 
[a encon trarme] [o sea traerme]

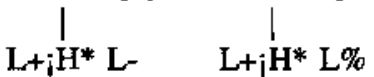
(Carmen M., ME-053-11M-00, CD-1, Pista 5)

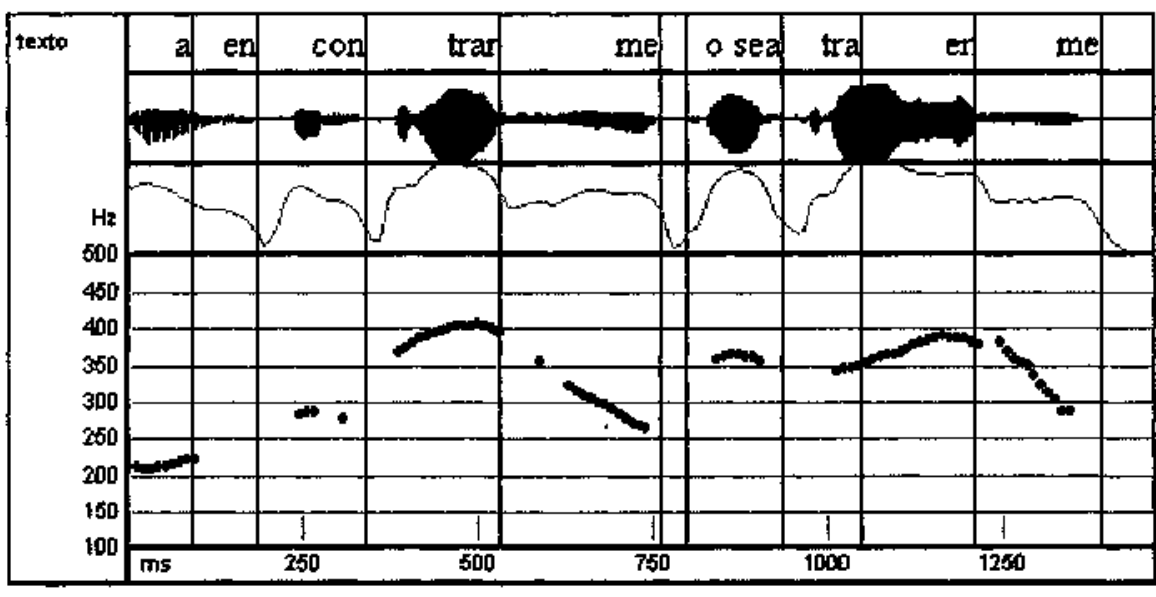

FIGURA 19.-A encontrarme o sea traerme.

La misma hablante produjo el ejemplo de la figura 20 , de nuevo con acento circunflejo en la frase intermedia:

[siempre han andado conmigo] [adonde voy] [andan conmigo]

$$
\mathrm{L}+\mathrm{HH}^{*} \mathrm{~L}-
$$

(Carmen M., ME-053-11M-00, CD-1, Pista 5)

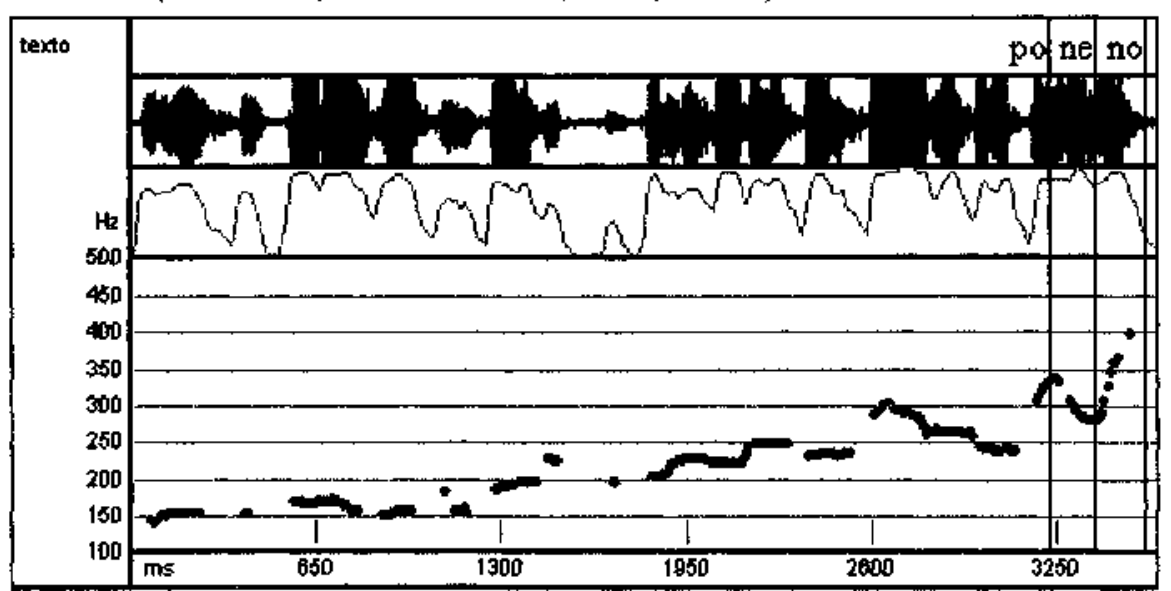

FIGURA 20.-Siempre han andado conmigo adonde voy andan conmigo. 
Por fin, el acento circunflejo es compatible con los casos de escalonamiento ascendente global, como el que se muestra aquí, donde el patrón se asigna a la frase intermedia:

[y si está media arrugada] [pues también le da un planchón] [y ya se lo pone] [no]

$\mathrm{L}+\mathrm{H}^{*} \mathrm{~L}-$

(Carmen C., ME-122-13M-01, CD-1, Pista 5)

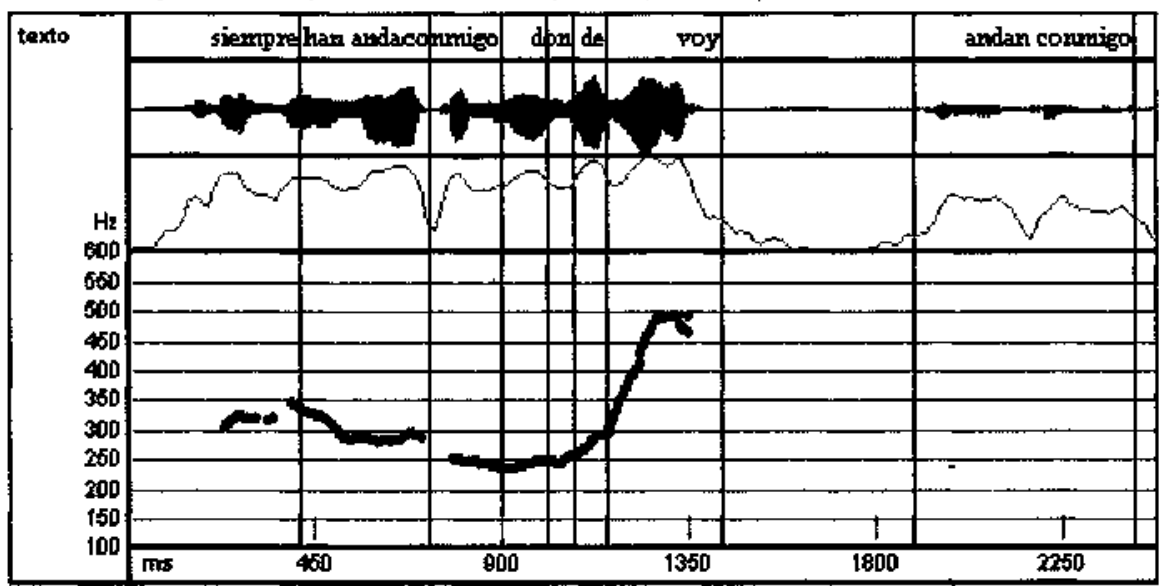

FIGURA 21.-Y si está medio arrugada pues también le da un planchón y ya se lo pone no.

\section{CONCLUSIONES}

Se pueden proponer cuatro conclusiones generales.

a) Lo que parece desencadenar la percepción de la configuración melódica como circunfleja es el acento nuclear $\mathrm{L}+{ }_{i} \mathrm{H}^{*}$ seguido por algún tipo de descenso, sea L\% o L-.

b) Hay por lo menos dos estructuras tonemáticas que aprovechan ese patrón general. Una es $\mathrm{L}+\mathrm{iH}^{*} \mathrm{~L} \%$, y otra $\mathrm{L}+\mathrm{i}^{*} \mathrm{~L}-\mathrm{H} \%$. Además, varias otras estructuras se acercan a esos dos patrones más característicos, pero difieren de ellos en diferentes aspectos: una elevación menos pronunciada (descrita como $\mathrm{L}+\mathrm{H}^{*}$ ), ausencia de descenso posterior al pico tonal (que adopta las formas $\mathbf{M} \%, \mathbf{H} \%, \mathbf{H}-$ ). Además, existe un número interesante de casos de declarativas descendentes del tipo $\mathrm{L}^{*} \mathrm{~L} \%$.

c) El promedio ponderado de ascenso de los patrones $\mathrm{A}\left(\mathrm{L}+; \mathrm{H}^{*} \mathrm{~L} \%\right)$ y $\mathrm{C}$ (básicamente $\mathrm{L}+\mathrm{i} \mathrm{H}^{*} \mathrm{~L}-\mathrm{H} \%$ ) es de 4.40 st, y el descenso es de 3.44 st. En $\mathrm{Hz}$, esto viene suponiendo que los hombres ascienden unos $34 \mathrm{~Hz}$ y descienden 
unos $27 \mathrm{~Hz}$, y las mujeres ascienden unos $69 \mathrm{~Hz}$ y descienden unos $85 \mathrm{~Hz}$. Los picos tonales de las configuraciones circunflejas se presentan normalmente en la parte final de la sílaba tónica. En cuanto a la duración de las silabas, el tonema asociado al patrón $C$ es notoriamente más largo, de $464.7 \mathrm{~ms}$, como corresponde al espacio necesario para desenvolver $\mathrm{L}-\mathrm{H} \%$; sigue en duración el patrón A (409.6 ms) y el patrón B (346.8 ms).

d) Por fin, en cuanto a los aspectos sociolingüísticos, las principales diferencias mostradas por los informantes de nivel sociocultural bajo se presentaron en el patrón $\mathrm{L}+\mathrm{j} \mathrm{H}^{*} \mathrm{~L}-\mathrm{H} \%$, mucho más común entre hombres que entre mujeres. Aunque los ejemplos obtenidos son perfectamente normales, formas exageradas de la configuración pueden llegar a estereotiparse y estigmatizarse. Será necesario examinar en trabajos posteriores las diferencias con estratos poblacionales medios y altos. La expectativa, por el momento, es que las configuraciones circunflejas en general y las del patrón $\mathrm{C}$ en particular son menos abundantes entre mujeres, cuanto más se asciende en la escala social y cuanto más formal es el estilo de habla. Pero todo esto último precisa confirmarse. 